\title{
Transmission Property of Directly Modulated Signals Enhanced by a Micro-ring
} Resonator

An, Yi; Lorences Riesgo, Abel; Seoane, Jorge; Ding, Yunhong; Ou, Haiyan; Peucheret, Christophe

Published in:

Proceedings of the 17th OptoElectronics and Communications Conference

Link to article, DOI:

10.1109/OECC.2012.6276694

Publication date:

2012

Link back to DTU Orbit

Citation (APA):

An, Y., Lorences Riesgo, A., Seoane, J., Ding, Y., Ou, H., \& Peucheret, C. (2012). Transmission Property of Directly Modulated Signals Enhanced by a Micro-ring Resonator. In Proceedings of the 17th OptoElectronics and Communications Conference (pp. 915-916). IEEE. https://doi.org/10.1109/OECC.2012.6276694

\section{General rights}

Copyright and moral rights for the publications made accessible in the public portal are retained by the authors and/or other copyright owners and it is a condition of accessing publications that users recognise and abide by the legal requirements associated with these rights.

- Users may download and print one copy of any publication from the public portal for the purpose of private study or research.

- You may not further distribute the material or use it for any profit-making activity or commercial gain

- You may freely distribute the URL identifying the publication in the public portal 


\title{
Transmission Property of Directly Modulated Signals Enhanced by a Micro-ring Resonator
}

\author{
Yi An, Abel Lorences Riesgo, Jorge Seoane, Yunhong Ding, Haiyan Ou, \\ and Christophe Peucheret \\ DTU Fotonik, Department of Photonics Engineering, Technical University of Denmark, DK-2800 Kgs. Lyngby, Denmark
}

\begin{abstract}
A silicon micro-ring resonator is used to enhance the modulation speed of a 10-Gbit/s directly modulated laser to $40 \mathrm{Gbit} / \mathrm{s}$. The generated signal is transmitted error free over $4.5 \mathrm{~km}$ SSMF. Dispersion tolerance is also studied.
\end{abstract}

\section{INTRODUCTION}

The ubiquitous demand for bandwidth triggered by the introduction of new services such as high-definition video is setting new requirements for short-reach applications, for instance in access and local area networks. For those applications, directly modulated lasers (DMLs) are often preferred over conventional external modulation schemes due to cost, footprint and power consumption constraints. Even though edgeemitting DMLs [1] and vertical-cavity surface-emitting lasers (VCSELs) [2] capable of operating at $40 \mathrm{Gbit} / \mathrm{s}$ have been demonstrated, generating and transmitting such high-speed directly-modulated signals error-free, i.e. with a bit-error-ratio (BER) better than $10^{-9}$, is still challenging.

Chirped managed lasers (CMLs), where direct modulation is followed by optical filtering rely on the conversion of the adiabatic chirp of the laser to intensity modulation, thereby generating dispersion-tolerant high extinction ratio (ER) signals [3]. Various optical filter technologies have been employed for this purpose, including fibre Bragg gratings, thin-film filters, or delay interferometers. However, these solutions are not always applicable to short range links since such optical filters tend to be bulky and unsuitable for integration.

We have recently proposed and demonstrated a novel transmitter design using a silicon micro-ring resonator (MRR) to enhance the modulation speed of a commercially available $10 \mathrm{Gbit} / \mathrm{s}$ DML up to $40 \mathrm{Gbit} / \mathrm{s}$ with error-free performance [4]. The transmission of such signals over optical fibres has however not been analyzed yet. In this paper, we report the first study of the transmission performance of directly modulated signals enhanced by an MRR over standard single mode fibre

This work was supported by the $7^{\text {th }}$ framework programme of the European Commission through the "Developing Aircraft Photonic Networks" (DAPHNE, ref. 233709) project, the Danish National Advanced Technology Foundation through the "Self-configurable Optical Links" (ref. 058-2009-3) project and the EURO-FOS (ref. 224402) network of excellence.
(SSMF). Error-free transmission with moderate penalty is experimentally demonstrated at $40 \mathrm{Gbit} / \mathrm{s}$ over up to $4.5 \mathrm{~km}$ SSMF. Numerical studies are furthermore used to discuss the optimum MRR design.

\section{EXPERIMENTAL SETUP}

As shown in Fig. 1, a commercially available DFB laser diode (NEL), designed for operating at $10 \mathrm{Gbit} / \mathrm{s}$, was directly modulated at $40 \mathrm{Gbit} / \mathrm{s}$ with a $2^{11}-1$ non return-to-zero (NRZ) pseudo-random binary sequence (PRBS). The DML was biased at $75 \mathrm{~mA}$ and modulated with $2.5 \mathrm{~V}$ peak-to-peak signal. Such a high bias current allows the adiabatic chip to dominate over the transient chirp. The modulated signal was then coupled to the MRR and collected again via tapered fibres. An erbiumdoped fibre amplifier (EDFA) was used to compensate the free-space coupling loss, followed by a $2 \mathrm{~nm}$ bandpass filter (BPF) for noise reduction. The filter was chosen to be wide enough to avoid introduction of any extra filtering which could impact the result. The signal was then either connected to the receiver (back-to-back), or launched to a variable length of SSMF. At the end of the link, the signal was received in a pre-amplified optical receiver.

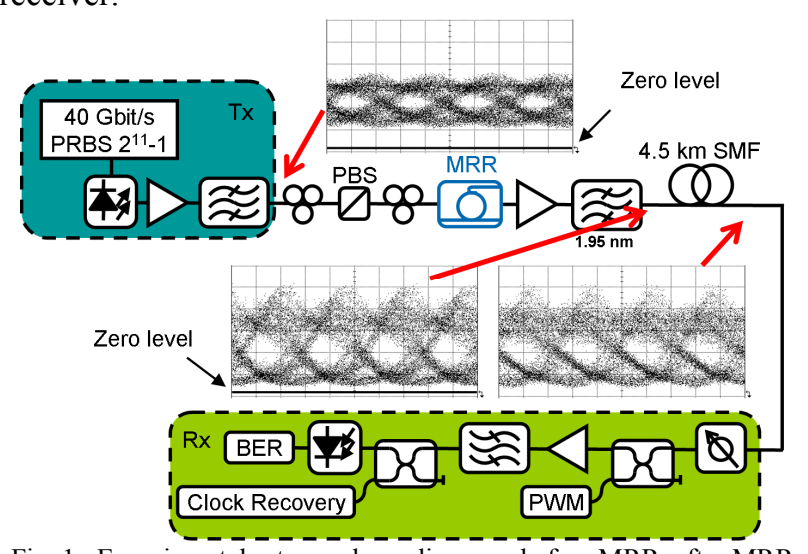

Fig. 1. Experimental setup and eye diagrams before MRR, after MRR and after $4.5 \mathrm{~km}$ SSMF transmission

The MRR used in this work was fabricated on a silicon-on-insulator platform by electron-beam lithography followed by reactive ion etching according to the process described in details in [5]. It had a free spectral range (FSR) of $200 \mathrm{GHz}$, corresponding to the standard wavelength division multiplexing grid and a measured Q-factor of 3300. The through port of the 
resonator was used to filter the DML output spectrum.

\section{RESULTS AND DISCUSSIONS}

The DML was designed to operate at $10 \mathrm{Gbit} / \mathrm{s}$, where a sensitivity $\left(\mathrm{BER}=10^{-9}\right)$ of $-30 \mathrm{dBm}$ was measured with a nominal bias of $45 \mathrm{~mA}$, which is a good compromise between a signal affected by relaxation oscillations and associated transient chirp (low bias) and a low extinction ratio (high bias). When operating at $40 \mathrm{Gbit} / \mathrm{s}$ with $75 \mathrm{~mA}$ bias, an error floor is present, as shown in Fig. 2(b), and the BER is limited to $7.4 \times 10^{-6}$ at $-15 \mathrm{dBm}$ received power. Thanks to the MRR, the BER is improved to $10^{-10}$ with the same received power. The eye diagram is significantly opened and the " 0 " level is largely suppressed, at the expense of some overshoot on the "1" level, as can be seen in Fig. 1. The sensitivity at $10^{-9}$ was about $-17.2 \mathrm{dBm}$ and the optimum detuning (detuning of the MRR notch to the long-wavelength side of the DML spectrum, as shown in Fig. 2(a)) was $0.2 \mathrm{~nm}$ [4].

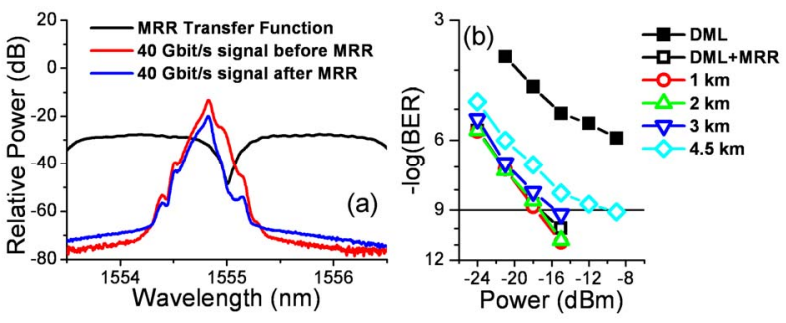

Fig. 2. Experimental results: (a) Signal spectra before and after the MRR and (b) BER performance at the DML output, after the MRR and after different length of SSMFs.

Using the proposed transmitter, the signal was transmitted error free up to $4.5 \mathrm{~km}$ SSMF (equivalent to $76.5 \mathrm{ps} / \mathrm{nm}$ dispersion) without dispersion compensation, as shown in Fig. 2(b). For transmission up to $3 \mathrm{~km}$, no significant BER penalty was noticed. However, after $4.5 \mathrm{~km}$, an error floor starts appearing.

The tolerance to negative dispersion was also studied by transmitting the signal through different lengths of dispersion compensating fibre (DCF). The sensitivity at $10^{-9}$ for different amounts of dispersion can be found in Fig. 3(a). The dispersion tolerance is found to be asymmetric with better performance observed for positive dispersion.

In order to interpret those results and study the impact of different MRR designs on the transmission performance, the sensitivity of the signal generated by the proposed transmitter was evaluated numerically as a function of dispersion. The laser parameters were extracted from the DFB laser used in the experiment. The signal generated with $42.8 \mathrm{Gbit} / \mathrm{s}$ direct modulation had a $2 \mathrm{~dB}$ ER and $12 \mathrm{GHz}$ adiabatic chirp. The MRR parameters can be found in Table I. The MRR used in the experiment was fitted numerically, corresponding to MRR3 in Table I.

The sensitivity was evaluated at $\mathrm{BER}=10^{-3}$ using Monte Carlo error counting. The numerical results are represented in Fig. 3 (b) and show a good qualitative match with the experimental measurements. From the simulations it is possible to conclude that the transmission dispersion tolerance is affected by the dispersion of the MRR transfer function. Since the MRR with lower coupling coefficient introduces more positive dispersion to the signal, it results in a reduced dispersion tolerance in the transmission fibre.
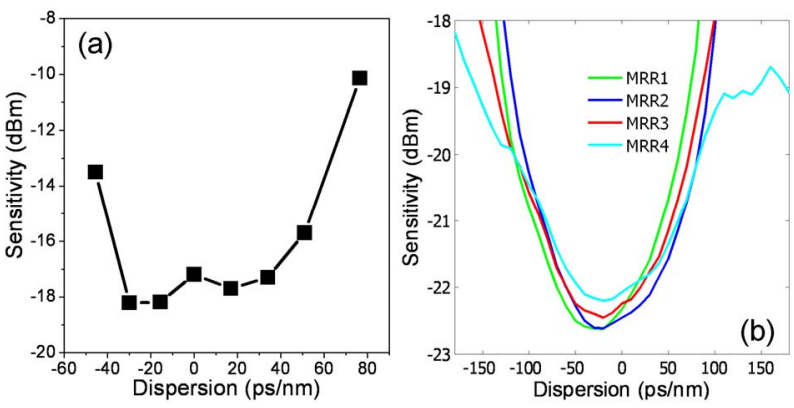

Fig. 3. Dispersion tolerance: (a) Experimental results of sensitivity $\left(\mathrm{BER}=10^{-9}\right)$ vs. dispersion. (b) Numerical results of sensitivity $\left(\mathrm{BER}=10^{-3}\right)$ vs. dispersion (b).

TABLE I::MRR PARAMETERS

\begin{tabular}{|c|c|c|}
\hline MRR Name & $\begin{array}{c}\text { FSG } \\
(\mathrm{GHz})\end{array}$ & $\begin{array}{c}\text { Coupling } \\
\text { Coefficient, } \\
\kappa^{2}[5]\end{array}$ \\
\hline MRR1 & 100 & 0.6 \\
\hline MRR2 & 100 & 0.8 \\
\hline MRR3 & 200 & 0.6 \\
\hline MRR4 & 200 & 0.8 \\
\hline
\end{tabular}

\section{Conclusions}

We have shown that a newly proposed scheme where a silicon MRR is used to enhance the modulation speed of a DML is robust to transmission over SSMF. Transmission of a $40 \mathrm{Gbit} / \mathrm{s}$ signal generated using a standard commercially available $10 \mathrm{Gbit} / \mathrm{s}$ DFB laser is demonstrated error-free and with moderate penalty up to $4.5 \mathrm{~km}$. The error-free range was experimentally determined to $-50 \sim 80 \mathrm{ps} / \mathrm{nm}$ dispersion. The influence of the MRR dispersion was clarified using numerical simulations. The proposed scheme can be scaled up to higher bit rates and to multi-channel operation. It can also be straightforwardly adapted to VCSEL sources, resulting in a potential low-cost transmitter for short-reach networks.

\section{REFERENCES}

[1] T. Tadokoro, W. Kobayashi, T. Fujisawa, T. Yamanaka and F. Kano, Optical Fiber Communication Conference (OFC/NFOEC), Paper OWD1, 2011.

[2] W. Hofmann, D. Müller, P. Wolf, A. Mutig, T. Gründl, G. Böhm, D. Bimberg and M.-C. Amann, Electron. Lett., vol. 47, pp. 270-271, 2011.

[3] D. Mahgerefteh, Y. Matsui, X. Zheng and K. McCallion, IEEE J. Sel. Top. Quantum Electron., vol. 16, pp. 11261139, 2010.

[4] Y. An, A. L. Riesgo, J. Seoane, Y. Ding, H. Ou and C. Peucheret, IEEE Optical Interconnect Conference., Paper TUB2, 2012.

[5] Y. Ding, J. Xu, C. Peucheret, M. Pu, L. Liu, J. Seoane, H. Ou, X. Zhang, and D. Huang, J. Lightwave Technol., vol. 29, pp. 677-684, 2011. 